\title{
Composição gravimétrica e estimativa de geração per capita municipal de resíduos sólidos urbanos destinados ao Aterro Sanitário de Palmeira das Missões, Rio Grande do Sul, Brasil
}

\section{Lucimara Bragagnolo ${ }^{1}$, Suéllen Tonatto Ferrazzo ${ }^{2}$, Fernanda Machado Brum ${ }^{3}$, Eduardo Pavan Korf ${ }^{1}$ e Altemir José Mossi ${ }^{1}$}

\footnotetext{
${ }^{1}$ Universidade Federal da Fronteira Sul. Campus Erechim. Rodovia RS 135, km 72. Erechim-RS, Brasil (CEP 99700-000).E-mail: lucimarabragagnolo@estudante.edu.uffs.br.

${ }^{2}$ Universidade Federal do Rio Grande do Sul. Avenida Osvaldo Aranha, 99. Bom Fim. Porto Alegre-RS, Brasil (CEP 90035-190).

${ }^{3}$ Centro de Ensino Superior Riograndense. Rodovia Leonel de Moura Brizola, BR 386, km 138. Beira Campo. Sarandi-RS, Brasil (CEP 99560-000).
}

Resumo. A gradativa expansão econômica, acelerada urbanização e contínuas melhorias dos padrões de vida da sociedade têm resultado no crescimento da geração per capita de resíduos sólidos urbanos, principalmente em países em desenvolvimento, como o Brasil. 0 referido parâmetro e a composição gravimétrica são importantes para o planejamento adequado do sistema de gerenciamento destes resíduos, porém, são altamente variáveis conforme as características de cada população e localidade. Sendo assim, este estudo teve por objetivo determinar a composição gravimétrica dos resíduos sólidos urbanos que são destinados ao aterro sanitário, localizado no Município de Palmeira das Missões, Rio Grande do Sul, Brasil, e estimar a geração per capita de resíduos de cada município atendido pelo aterro, bem como traçar comparativos com parâmetros socioeconômicos, e entre outras regiões do país e do mundo. A composição gravimétrica revelou que 41,8\% dos resíduos sólidos urbanos é composto por resíduo orgânico, correspondendo a uma parcela semelhante à média da Região Sul e da nacional. Já os resíduos recicláveis representam $58,2 \%$ do total, diferenciando-se da parcela média das regiões brasileiras e de outros países. Verificou-se que, dos 27 municípios atendidos pelo aterro, 7,7\% apresentam geração per capita de resíduos sólidos urbanos acima da média da Região Sul, e em $37 \%$ não há coleta seletiva. Referente aos fatores, número de habitantes e PIB per capita, nenhum se correlacionou significativamente com a geração per capita destes resíduos.

Palavras-chave: Composição gravimétrica; Geração per capita; Disposição final; Reciclagem; Rejeitos.

Recebido

28/02/2020

Aceito

26/08/2020

Disponível on line

$27 / 08 / 2020$

Publicado

$31 / 08 / 2020$

Acesso aberto

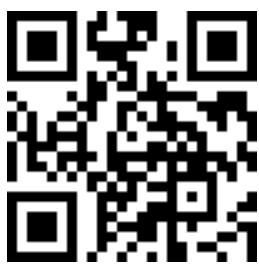

ORCID

(D) 0000-0001-6143-525X Lucimara Bragagnolo

(1) 0000-0003-3413-4747

Suéllen Tonatto

Ferrazzo

ISSN 2359-1412/RBGAS-2020-0030/2020/7/16/31/953

Rev. Bras. Gest. Amb. Sustent.

http://revista.ecogestaobrasil.net 
Abstract. Gravimetric composition and estimation of per capita municipal solid waste generation destined for the Landfill of Palmeira das Missões, Rio Grande do Sul, Brazil. The economic growth, accelerated urbanization, and continuous improvements in society's living standards have resulted in the growth of the per capita municipal solid waste generation, especially in developing countries such as Brazil. This parameter and the gravimetric composition are important for an adequate planning of the waste management system. However, these are highly variable according to the characteristics of each population and locality. Thus, this study aimed to determinate the gravimetric composition of the municipal solid waste destined to a sanitary landfill, located in Palmeira das Missões Municipality, Rio Grande do Sul State, Brazil, and to estimate the per capita generation for each city served by this landfill, as well as to draw a comparison with the socioeconomic parameters and with others country and regions. The gravimetric composition showed that $41.8 \%$ of the municipal solid waste is composed of organic waste, corresponding to the South Region and the national average. On the other hand, recyclable waste represents $58,2 \%$ of the total, differing from the Brazilian regions and other countries average. It was verified that of the 27 municipalities served by the landfill, $7.7 \%$ presented a municipal solid waste per capita generation above the Brazilian South Region average, and in 37\% there is no selective collection. Regarding the socioeconomic factors, the population and gross domestic product per capita showed no significant correlation with the per capita generation of these solid wastes.

Keywords: Gravimetric composition; Per capita generation; Final disposition; Recycling; Waste.

\author{
0000-0002-7058-6890 \\ Fernanda Machado \\ Brum \\ D 0000-0003-2041-0173 \\ Eduardo Pavan Korf \\ D 0000-0002-7917-450X \\ Altemir José Mossi
}

\section{Introdução}

A produção de resíduos sólidos vem crescendo abundantemente nos últimos anos (Alkmin e Uberto Jr, 2017), com uma estimativa global de 4 bilhões de toneladas por ano, sendo que entre 1,6 a 2 bilhões correspondem aos resíduos sólidos urbanos (Gutberlet, 2015). Este cenário é decorrente do aumento considerável da urbanização, do padrão de consumo e da mudança de hábitos alimentares, características evidenciadas, principalmente nos países em desenvolvimento. Neste cenário, torna-se cada vez mais necessária uma gestão de resíduos sólidos eficiente, demandando conhecimento e alternativas para que o destino final dos RSU seja ambientalmente correto, consequentemente reduzindo impactos ambientais (Agbozu et al., 2015; Khan et al., 2016) e a utilização de novas áreas (Wang et al., 2018), mitigando mudanças climáticas e reciclando recursos (Wang et al., 2020).

No que se refere à geração desse tipo de resíduo, observou-se no Brasil um crescimento de $1 \%$ entre 2016 e 2017, enquanto a geração per capita de resíduos sólidos urbanos registrou um aumento de quase 0,5\% no mesmo período (ABRELPE, 2017). Em nível global, enquanto que, há uma década, a geração de resíduos sólidos urbanos aproximava-se de 0,68 bilhões de toneladas por ano, os níveis mais recentes atingiram, 
aproximadamente, 1,3 bilhões de toneladas/ano. Conforme perspectiva atual, o esperado é que tais níveis sejam de 2,2 bilhões de toneladas por ano até 2025 (Pellera et al., 2016).

Em geral, a opção mais utilizada para a disposição dos resíduos sólidos urbanos ainda são os aterros sanitários, uma vez que esta tecnologia demanda de menores investimentos (Demirbas, 2011), entretanto, é a menos adequada devido ao alto potencial de contaminação de solo e água (He et al., 2019; Mishra et al., 2019; Torrente-Valásquez et al., 2020) e as emissões de gases de efeito estufa (Mohsen e Abbassi, 2020; Torrente-Valásquez et al., 2020; Wang et al., 2020). Em cidades como Pequim, na China, a maior parte dos resíduos gerados é coletada e transportada para grandes estações de transferência e depois para aterros $(64,6 \%)$, ou para as plantas de compostagem $(3,5 \%)$. 0 volume restante é transportado diretamente para aterros sanitários $(28,4 \%)$ ou despejos abertos (3,5\%) (Zhao et al., 2011). Em países pertencentes à União Europeia, os resíduos sólidos urbanos são gerenciados através de aterros sanitários $(33,6 \%)$, incineração $(24,2 \%)$, reciclagem $(27,4 \%)$ e compostagem e digestão anaeróbica $(14,8 \%)$ (Colazo et al., 2015). Na índia, 70\% dos resíduos sólidos urbanos é coletado e dessa parcela, $12 \%$ é processado corretamente e o restante descartado em "lixões" (Manjunatha et al., 2020). No Brasil, de acordo com o último relatório disponibilizado pela ABRELPE (2017), 59,1\% dos resíduos gerados são enviados para aterros sanitários, 22,9\% para aterros considerados controlados e 18\% ainda são enviados para lixões. Já na Região Sul do país, no ano de 2017, mais precisamente em 1191 municípios, a geração de resíduos sólidos urbanos correspondeu a 22.429 t diárias, sendo que, 70,2\% e 18,2\% foram encaminhadas, respectivamente à aterro sanitário e a aterro controlado, e 11,6\% dispostas em lixões (Abrelpe, 2017). Desta região, pode-se destacar o estado do Rio Grande do Sul com uma produção diária de 8.643 t de resíduos sólidos urbanos (Brina et al., 2018).

De acordo com Alfaia et al. (2017), enquanto que países já desenvolvidos, como os Estados Unidos, implementaram leis e programas de resíduos sólidos ainda nos anos 70, o Brasil instituiu sua Política Nacional de Resíduos Sólidos apenas no ano de 2010 (Brasil, 2010). Desta forma, o país ainda possui um longo caminho de desenvolvimento de políticas públicas para alcançar um nível de gerenciamento de resíduos sólidos desejado, em que se prefira adotar outras alternativas de destinação de resíduos, mais sustentáveis e ecológicas, além da disposição em aterros sanitários, medida mais utilizada atualmente.

Neste sentido, considerando que, no país, a forma prevalecente de disposição final de resíduos sólidos urbanos é em aterros sanitários, é imprescindível que sejam realizados estudos que envolvam a caracterização das propriedades desses resíduos, de forma a permitir o desenvolvimento de tecnologias mais eficientes e seguras no que se refere aos projetos desses aterros (Miguel et al., 2016). Tais pesquisas ainda auxiliam em questões de monitoramento ambiental, de compreensão do processo de decomposição dos resíduos, bem como no cálculo de estimativa da vida útil da área de disposição (Monteiro e Jucá, 1999). Além disso, informações sobre as categorias dos resíduos sólidos urbanos, e suas respectivas quantidades, são considerados subsídios básicos para a elaboração de políticas, planos e otimização de sistemas de gerenciamento de resíduos (Liu et al., 2015; Dehghanifard e Dehghani, 2018; Hoque e Rahman, 2020; Torrente-Valásquez et al., 2020).

Dentre as principais propriedades a serem avaliadas nesses estudos, destaca-se a composição gravimétrica, fundamental para a compreensão do comportamento dos resíduos, e que é expressa pela relação entre a massa de cada componente com a massa total da amostra de resíduos, em percentual (Melo e Jucá, 2000). A referida propriedade também permite estimar o grau de contaminação dos materiais a serem dispostos em determinada área. Contudo, na literatura, ainda se observa uma escassez de estudos que avaliem a composição de resíduos sólidos urbanos em aterros sanitários (Mattei e Escosteguy, 2007) ou ainda, que realizem o levantamento de estatísticas referente à produção destes resíduos, de forma global. A última questão ocorre porque, segundo Obe et al. (2017), muitas informações de resíduos sólidos urbanos, como a geração per capita

Rev. Bras. Gest. Amb. Sustent., 2020, vol. 7, n. 16, p. 953-970. 
ou composição gravimétrica, são estimadas considerando os resíduos que chegam ao aterro sanitário, porém parte da produção dos resíduos pode passar por triagem ou receber outra destinação final antes mesmo de chegar ao aterro, deixando de ser contabilizada. A composição gravimétrica, bem como as taxas de geração de resíduos sólidos urbanos são parâmetros altamente variáveis para cada região, e são influenciados, basicamente pelo desenvolvimento econômico, grau de industrialização, hábitos sociais, número de habitantes, legislações, clima local, dentre outros (Marshall e Farahbakhsh, 2013; Slagstad e Brattebø, 2013; Dehghanifard e Dehghani, 2018; Ramachandra et al., 2018). Dessa forma, é imprescindível que esta caracterização seja realizada em âmbito local, de forma a possibilitar uma maior representatividade e confiabilidade das informações.

Considerando que informações sobre a caracterização e disposição de resíduos são importantes para compreensão e planejamento do sistema de gerenciamento dos resíduos sólidos urbanos, mas que apresentam discrepâncias e variações entre diferentes estudos e regiões, o presente artigo tem por objetivo apresentar os resultados obtidos por meio da caracterização gravimétrica dos resíduos sólidos urbanos encaminhados à um aterro sanitário, localizado no município de Palmeira das Missões (RS), bem como uma avaliação comparativa entre este parâmetro e fatores econômicos dos municípios atendidos pelo aterro e entre outras regiões do Brasil e do Mundo. Objetivou-se, também, realizar uma estimativa da geração per capita de resíduos sólidos urbanos para cada um dos 27 munícipios que encaminham seus resíduos ao aterro sanitário de estudo.

\section{Metodologia}

\section{Caracterização da área de estudo}

O local de estudo refere-se a um aterro sanitário de uma empresa privada, que se localiza no município de Palmeira das Missões, pertencente a Microrregião de Carazinho e a Mesorregião Noroeste Rio-Grandense. Conforme a Norma ABNT NBR 10004, o aterro recebe apenas resíduos sólidos urbanos - Classe II (ABNT, 2004a) de 27 municípios.

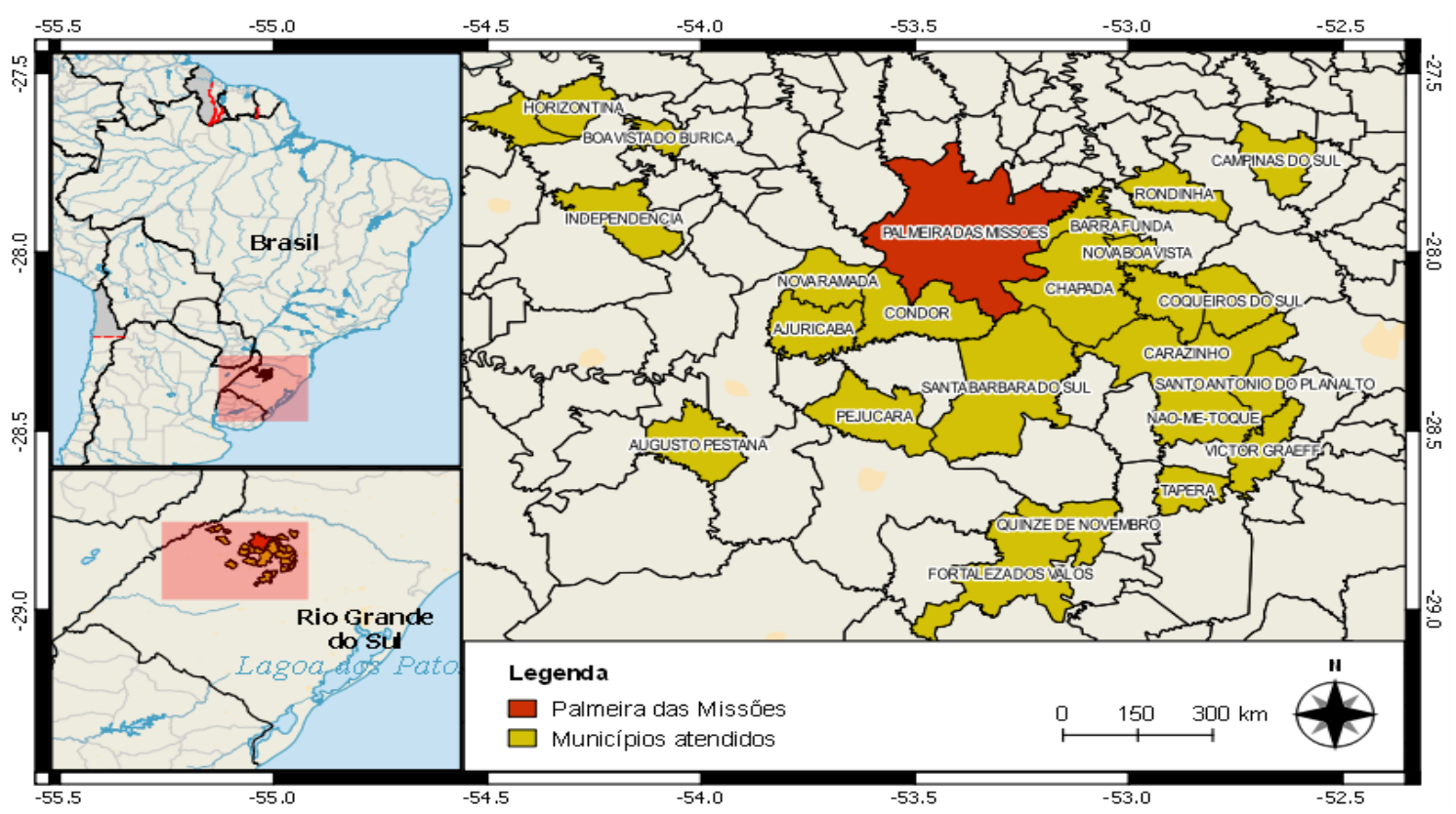

Figura 1. Mapa de localização de Palmeira das Missões e dos municípios atendidos pelo aterro sanitário. 
0 aterro está localizado às margens da estrada vicinal que liga Palmeira das Missões a São José das Missões, no km 05, a nordeste do centro urbano de Palmeira das Missões. As condições de acesso à área são adequadas ao tráfego de máquinas e veículos automotores em qualquer época do ano. A localização do município que abrange a área do aterro, bem como a localização dos municípios atendidos por ele (Figura 1).

\section{Metodologia de amostragem}

Considerando que a composição gravimétrica dos resíduos apresenta características de sazonalidade ao longo do ano, a amostragem dos resíduos foi realizada em três diferentes momentos, sendo eles nos meses de novembro de 2016, março e junho de 2017. Durante as campanhas de amostragem, realizou-se todo o acompanhamento durante as etapas de chegada dos caminhões, pesagem, seleção, classificação e disposição final dos resíduos nas células do aterro.

A caracterização dos resíduos em relação a sua composição gravimétrica foi executada com base na ABNT NBR 10007 (ABNT, 2004b), abrangendo os seguintes procedimentos:

a) Pesagem do carro coletor na chegada com os materiais e saída com o caminhão vazio;

b) Descarregamento dos resíduos na central de triagem;

c) Quarteamento dos resíduos até o volume final desejado para pesagem.

Para tanto, os resíduos descarregados na central de triagem foram separados de forma a obter uma amostra de $1 \mathrm{~m}^{3}$. A partir disso, os materiais foram misturados de forma a obter uma massa homogeneizada (Figura 2). Para essa etapa, foram utilizados os seguintes materiais: balança, um quadrado formado por réguas de madeira com as dimensões de $2 \mathrm{~m}$ x $2 \mathrm{~m}$, para a execução do processo de homogeneização e quarteamento dos resíduos; e containers para a pesagem dos resíduos. Em seguida, os resíduos foram devidamente classificados, da seguinte maneira:

a) Separação conforme a classe "Reciclável e não Reciclável".

b) Separação dos resíduos conforme sua composição (plástico, papelão, rejeito e reciclável, como metal, vidro entre outros) e acondicionamento em bags;

c) Pesagem de cada material, conforme a sua composição;

d) Encaminhamento do material orgânico e rejeito para as células de disposição;

e) Determinação dos percentuais constituintes dos resíduos sólidos, ou seja, da composição gravimétrica, através da seguinte Equação 1.

\section{$\mathrm{CG}(\%)=M_{c} / M_{t} \times 100$}

Sendo:

CG o percentual da composição gravimétrica (\%),

$\mathrm{M}_{\mathrm{C}}$ a massa do componente $(\mathrm{kg})$, e

$\mathrm{M}_{\mathrm{t}}$ a massa total da amostra $(\mathrm{kg})$. 

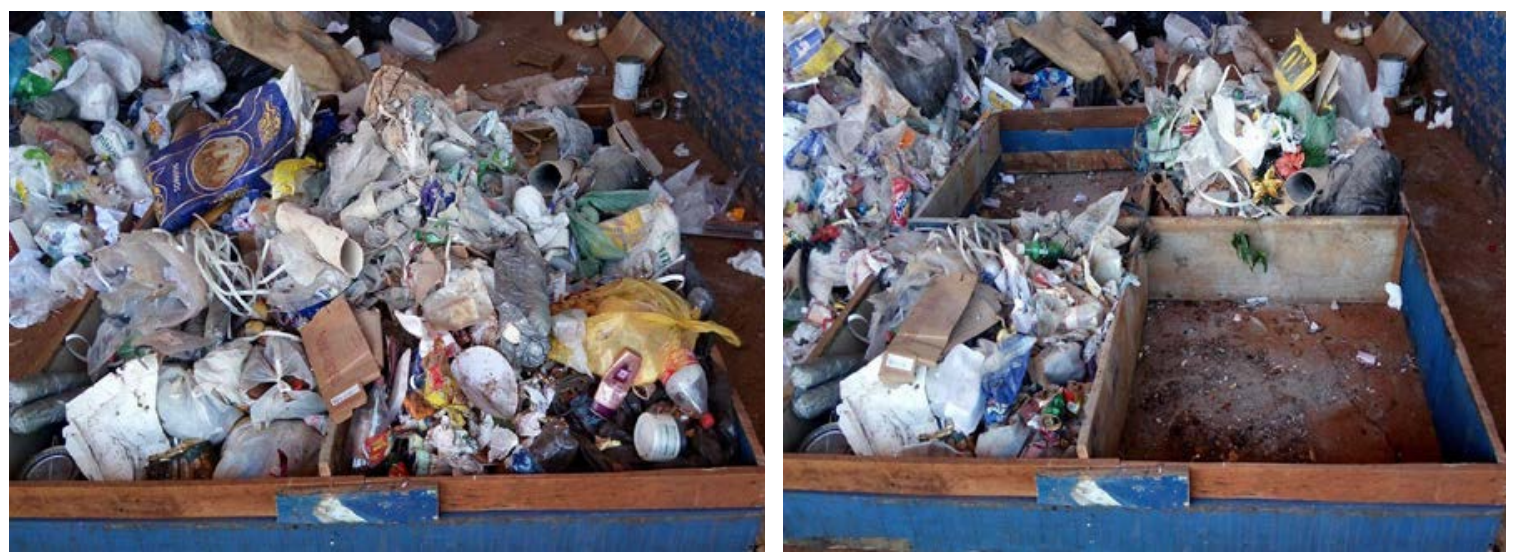

Figura 2. Processo de quartamento dos resíduos. Fonte: Elaborado pelos autores (2018).

Após a separação dos materiais na central de triagem, os resíduos foram encaminhados juntamente com o restante do material para Central de Triagem licenciada pelo município. Os materiais, mesmo quando não limpos, são encaminhados para 0 processo de venda, pois esses são posteriormente lavados, fragmentados e triturados. Todo esse processo está esquematizado na Figura 3.

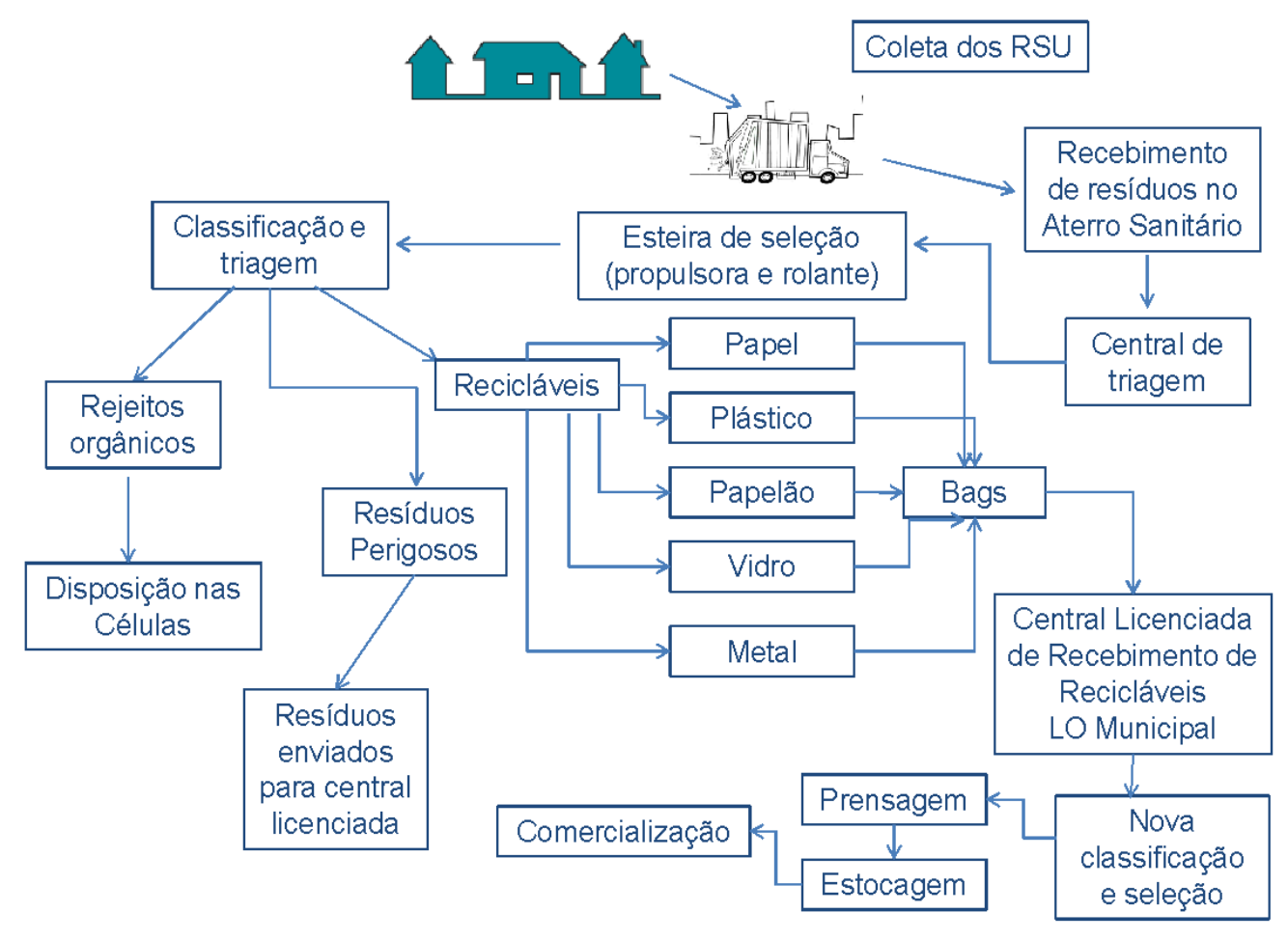

Figura 3. Fluxograma do processo da Central de triagem do aterro sanitário. 
Ainda se realizou um levantamento bibliográfico com o objetivo de comparar os resultados obtidos com cenários de outras regiões do Brasil e do mundo. Para tanto, buscou-se estudos que envolveram a caracterização gravimétrica de regiões consideradas desenvolvidas, não desenvolvidas e em desenvolvimento, bem como de regiões brasileiras.

Por fim, de forma a estimar a produção per capita dos resíduos de cada uma das 27 cidades que encaminham seus resíduos para aterramento nesse local, as informações do volume total de resíduos que chega ao aterro foram divididas pelo número total de habitantes de cada cidade, tendo como base os dados de população do censo de 2010,-do (IBGE, 2010). A partir disso, avaliou-se, estatisticamente, a relação do referido parâmetro com alguns fatores socioeconômicos levantados para cada município.

\section{Resultados e discussão}

A Figura 4 apresenta os resultados para da composição gravimétrica média dos resíduos sólidos urbanos que chegam ao aterro sanitário em estudo. Os resíduos considerados como rejeito referem-se aos resíduos de natureza orgânica ou não orgânica, que não estão adequados para o processo de reciclagem, por estarem misturados, ou, ainda, por não possuírem mais valor de mercado, estando suas possibilidades de reaproveitamento já esgotadas. Estes, juntamente com os resíduos orgânicos, resultaram em um percentual de $41,8 \%$ de todos os resíduos, sendo encaminhados para as células de disposição. Na literatura, observa-se que diversos municípios brasileiros apresentam um percentual de matéria orgânica em seus resíduos sólidos urbanos na faixa de 51,4 a 57,27\% (Münnich et al., 2006; Miguel et al., 2016; Alfaia et al., 2017), sendo que o valor encontrado no presente estudo está abaixo do limite inferior desse intervalo. Ainda, é importante destacar que a quantidade de resíduos orgânicos presentes influenciará nas características dos resíduos sólidos urbanos quando encaminhados para a disposição final, devido às alterações das propriedades de compressão, resistência ao cisalhamento e permeabilidade e, consequentemente, influenciando nos processos de biodegradação (Machado et al., 2010). Dessa forma, salienta-se a importância de conhecer e estudar as características dos resíduos que chegam aos locais de disposição, de modo a possibilitar a utilização de metodologias apropriadas e seguras ao ambiente.

Para a classe de "outros resíduos recicláveis", foram considerados os resíduos de metal, vidro e tecidos, os quais representam um percentual de $22,8 \%$ do total. Resíduos de plástico, como embalagens de produtos alimentícios, garrafas pet e sacolas representam um montante de 22,8\% dos resíduos. Já os resíduos de papel e papelão obtiveram 12,6\%. Percentuais de resíduos recicláveis semelhantes a estes, foram identificados no Rio de Janeiro, em que dos resíduos encaminhados aos aterros com potencial de reciclagem, $19,1 \%$ e 16,5\% correspondem à plástico e papel, respectivamente (Tirado-Soto e Zamberlan, 2013).

Segundo Oyake-Ombis et al. (2015), a proporção dos resíduos plásticos nos resíduos sólidos urbanos correlaciona-se positivamente com os níveis de desenvolvimento econômico. Em geral, nos últimos anos, análises de composição gravimétrica de resíduos têm demonstrado que o percentual de plásticos vem aumentando gradativamente, ao mesmo passo que a proporção de papel tem decrescido (Lima e Surluiga, 2000; Dehghanifard e Dehghani, 2018). Por exemplo, em cidades do Irã verificou-se que, ao passar dos anos, houve o aumento da porcentagem de plásticos nos resíduos sólidos urbanos e a minimização ou estabilização da parcela de papel. Considerando que o processo de reciclagem do plástico é mais difícil que o do papel, identifica-se a necessidade da criação de mecanismos para a redução do uso de plásticos e de incentivos a utilização de materiais recicláveis de origem orgânica (Dehghanifard e Dehghani, 2018).

Rev. Bras. Gest. Amb. Sustent., 2020, vol. 7, n. 16, p. 953-970. 

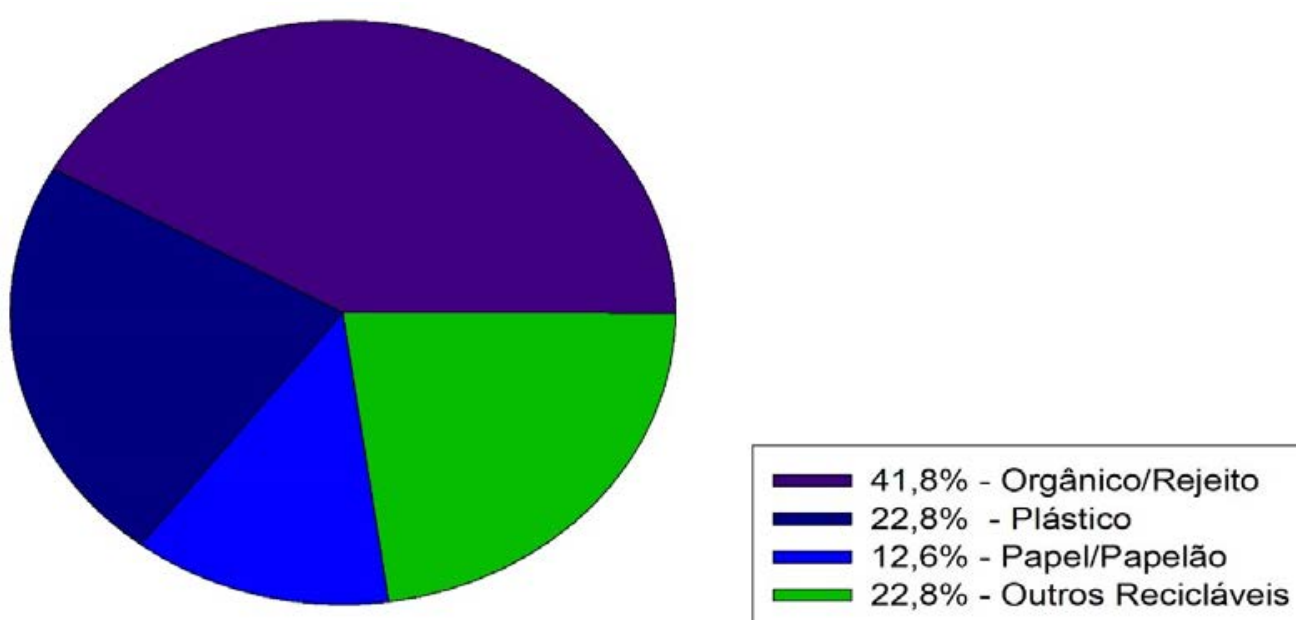

Figura 4. Composição gravimétrica de resíduos sólidos urbanos após o método de quarteamento.

Do total de resíduos sólidos urbanos enviado para o aterro sanitário, verificou-se que $58,2 \%$ é composto por resíduo reciclável. A grande parcela de resíduos recicláveis deve-se tanto a inexistência de coleta seletiva em 37\% municípios que encaminham seus resíduos ao aterro (Tabela 2), quanto pela separação inadequada desses, por desconhecimento ou falta de sensibilização, em casos em que há a presença da coleta seletiva (Fehr, 2007). Contudo, a percentagem dos municípios que encaminham seus resíduos sólidos urbanos ao aterro de estudo, que não realizam coleta seletiva (37\%) equipara-se ao percentual em nível nacional. De acordo com a-ABRELPE (2017), no Estado do Rio Grande do Sul, 10\% dos municípios ainda não adotaram essa forma de coleta, enquanto que, a nível nacional, o percentual é ainda maior, representando $30 \%$ de municípios sem esse processo. Ainda, embora a triagem seja realizada no local do aterro deste estudo, muitos dos resíduos que seriam considerados recicláveis acabam sendo encaminhados às células para disposição final, principalmente pela impossibilidade de recuperação, em decorrência da mistura com os materiais orgânicos.

Sendo assim, uma expressiva quantidade de resíduos recicláveis na composição gravimétrica dos resíduos sólidos urbanos pode ser considerada um indicativo da necessidade do desenvolvimento de políticas públicas de incentivo ao reaproveitamento e reciclagem destes materiais. Tais incentivos do poder público podem advir da elaboração de políticas e legislações que visam a disseminação da coleta seletiva e campanhas educacionais (Gonçalves-Dias, 2006; Wang et al., 2020), e a criação de cooperativas de carrinheiros e de reciclagem (Gonçalves-Dias, 2006), podendo incluir como exemplos, parcerias e/ou a concessão de benefícios às cooperativas de reciclagem, além de mecanismos econômicos e exigências legais versáteis voltados ao mercado (Puna e Baptista, 2008; Wang et al., 2020).

A partir da Figura 5, pode-se observar que os resultados obtidos neste estudo assemelham-se à composição gravimétrica média global (Hoornweg e Bhada-Tata, 2012), principalmente no que se refere ao percentual de orgânicos $(41,8 \%)$ e papel/papelão $(12,6 \%)$. Já em comparação com a geração de resíduos de acordo com a classe de renda (Tabela 1), verifica-se que os valores se enquadram entre as características de países que possuem renda média-alta e países de renda alta, com exceção da composição de plástico, que apresentou uma parcela mais expressiva $(22,8 \%)$.

De acordo com diversos autores (Ahmed e Ali, 2004; Hoornweg e Bhada-Tata, 2012; Alfaia et al., 2017; Obe et al., 2017), tem-se observado uma tendência de 
concentração superior de matéria orgânica em resíduos sólidos urbanos de países de baixa renda, quando comparada com países de renda alta. Nos países desenvolvidos, devido ao desenvolvimento e incentivo de programas de reciclagem, a composição de seus resíduos sólidos urbanos apresenta uma elevada fração de plásticos (Ahmed e Ali, 2004). De modo geral, quanto maior é a renda do país, maior será seu consumo e, consequentemente, maior será a quantidade de resíduos gerada. As considerações supracitadas corroboram com o estudo de Hoornweg e Bhada-Tata (2012), onde se verificou que menos embalagens de papel/plástico são utilizadas em locais que apresentam menor grau de desenvolvimento e também, nestas regiões, a produção de resíduos orgânicos é mais significativa.
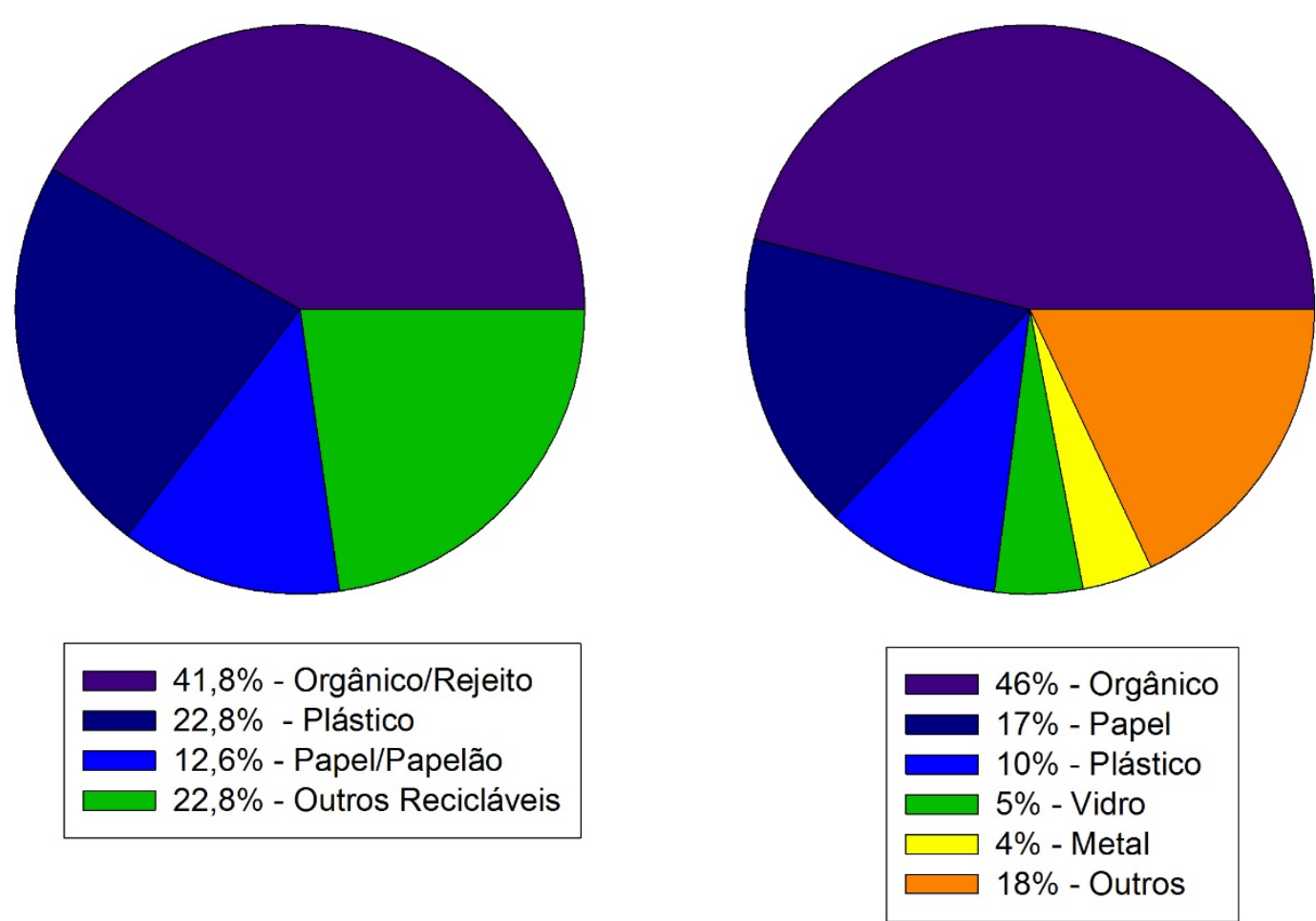

Figura 5. Composição gravimétrica do estudo (à esquerda) e em nível global (à direita). Fonte: Adaptado de Hoornweg e Bhada-Tata (2012).

Tabela 1. Tipos de composição gravimétrica com base no nível de renda.

\begin{tabular}{|l|c|c|c|c|c|c|}
\hline Nível de renda & $\begin{array}{c}\text { Orgânico } \\
\text { (\%) }\end{array}$ & $\begin{array}{c}\text { Papel } \\
\text { (\%) }\end{array}$ & $\begin{array}{c}\text { Plástico } \\
(\mathbf{\% )}\end{array}$ & $\begin{array}{c}\text { Vidro } \\
(\mathbf{\% )}\end{array}$ & $\begin{array}{c}\text { Metal } \\
(\mathbf{\% )}\end{array}$ & $\begin{array}{c}\text { Outros } \\
\mathbf{( \% )}\end{array}$ \\
\hline Baixa renda & 64 & 5 & 8 & 3 & 3 & 17 \\
\hline Média-baixa renda & 59 & 9 & 12 & 3 & 2 & 15 \\
\hline Média-alta renda & 54 & 14 & 11 & 5 & 3 & 13 \\
\hline Alta renda & 28 & 31 & 11 & 7 & 6 & 17 \\
\hline
\end{tabular}

Fonte: Adaptado de Hoornweg e Bhada-Tata (2012). 
Ainda, a composição gravimétrica dos resíduos sólidos urbanos deste estudo foi comparada com estudos de diferentes regiões, abrangendo países desenvolvidos como EUA e Reino Unido, países em desenvolvimento como China e Brasil, e a Quênia, país ainda subdesenvolvido, além de regiões Brasileiras como Norte, Sul e Nordeste. Conforme a Figura 6, a geração de resíduos de plástico, papel e papelão assemelha-se às quantidades geradas pela média nacional brasileira. Quanto aos resíduos considerados como outros recicláveis (metal, vidro e outros), a média encontrada no estudo demonstra ter valores próximos a região Sul e Nordeste do Brasil e a Quênia. Já os rejeitos e resíduos orgânicos apresentaram valores aproximados com a da região Sul do Brasil, essa que engloba a localização do aterro sanitário em estudo. 0 percentual de resíduos orgânicos observado, de 41,8\% (Figura 4), assemelha-se com a produção de outros países, como Quênia, Reino Unido e China, bem como com todas as regiões brasileiras e a média nacional. Os Estados Unidos se destaca nesse quesito, com o menor valor encontrado, de 18\%. As altas concentrações desse tipo de resíduo em todas as regiões do Brasil, Quênia e Reino Unido se deve, principalmente pela quantidade de alimentos desperdiçados que acaba sendo encaminhada para o aterro e pelas características de vida da população. Segundo a Organização de Alimentos e Agricultura das Nações Unidas (FAO, 2016), o desperdício de alimentos, em regiões de renda baixa, é resultado das limitações administrativas e das técnicas utilizadas durante todas etapas que envolvem o processamento dos alimentos.

Por outro lado, em países de renda média e alta, o desperdício de alimentos devese, essencialmente ao comportamento do consumidor e às políticas empregadas. Por exemplo, um planejamento inadequado de compras, bem como a não utilização dos produtos antes de seu vencimento, contribuem nessas estatísticas. Ainda, outro fator relacionado ao elevado percentual de rejeitos orgânicos refere-se à compostagem, que ainda não é considerada uma prática consolidada pela população, e que poderia resultar em um decréscimo expressivo dos resíduos encaminhados aos aterros sanitários (IPEA, 2012).

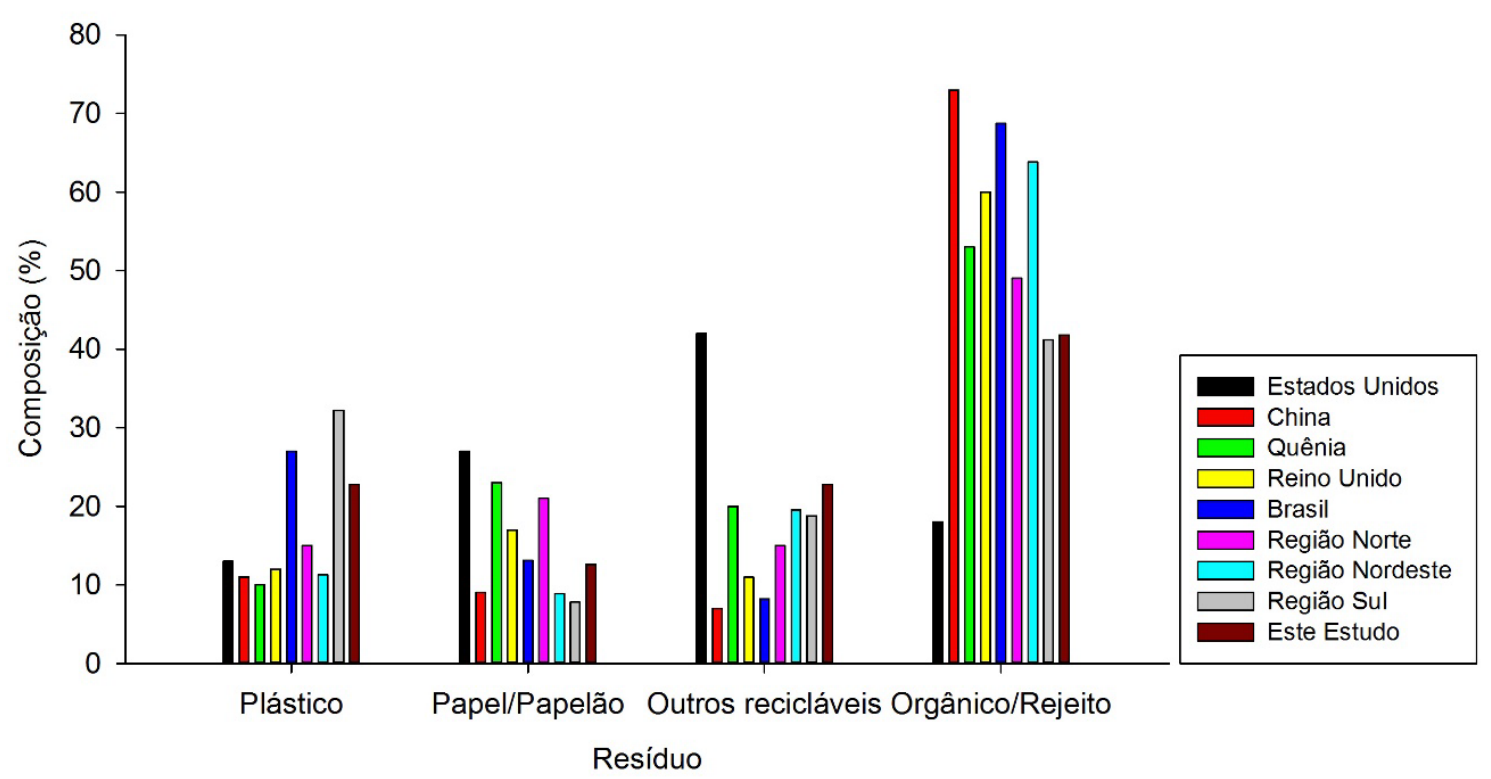

Figura 6. Comparação da composição gravimétrica de resíduos deste estudo com regiões do Brasil e outros países. Fonte: Mattei e Escosteguy (2007), Brasil (2011), Carvalho et al. (2013), Zhou et al. (2014), Barreto et al. (2015), Czajczyńska et al. (2017). 
Neste contexto, também é importante destacar que a geração de resíduos sólidos urbanos correlaciona-se de forma complexa com o desenvolvimento econômico e a dinâmica populacional, sendo estes, fatores específicos de cada sociedade (Chen et al., 2010; Wang et al., 2020). No que se refere a produção per capita de resíduos sólidos urbanos, de acordo com o relatório da ABRELPE (2017), a região Sul, que abrange os municípios que encaminham seus resíduos ao aterro de Palmeira das Missões, apresenta uma geração per capita de $0.75 \mathrm{~kg}^{-1}$.hab ${ }^{-1} \cdot \mathrm{dia}^{-1}$, representando o menor valor dentre as demais regiões do país (Figura 7). A partir disso, com o intuito de se obter uma caracterização quantitativa por município e realizar uma comparação com os dados médios da região Sul do Brasil, calculou-se a geração per capita de resíduos sólidos urbanos para cada um dos 27 municípios que utilizam o aterro sanitário de estudo. Com base nos dados da Tabela 2, a média diária de resíduo destinado ao aterro é de 10,4 t/dia. Dos 27 municípios atendidos pelo Aterro Sanitário, apenas Horizontina e Vitor Graeff obtiveram uma geração per capita de resíduos sólidos urbanos $\left(0,8\right.$ e $0,84 \mathrm{~kg}^{-1} \cdot \mathrm{hab}^{-1} \cdot \mathrm{dia}^{-1}$, respectivamente) superior à média de resíduos sólidos urbanos per capita na região Sul do Brasil $\left(0,75 \mathrm{~kg}^{-1} \cdot \mathrm{hab}^{-1} \cdot \mathrm{dia}^{-1}\right)$, correspondendo a 7,3\% dos municípios. Além disso, em $37 \%$ dos municípios ainda não dispõem de coleta seletiva de resíduos sólidos urbanos.

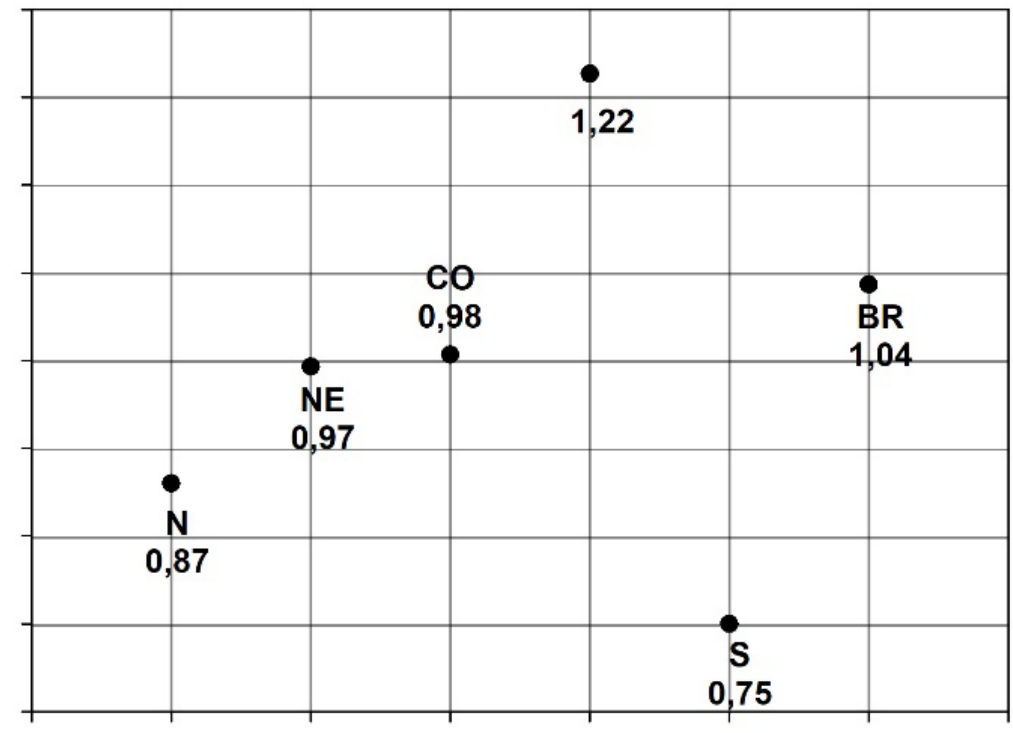

N - Região Norte

NE - Região Nordeste

CO - Região Centro Oeste

SE - Região Sudeste

S - Região Sul

BR - Brasil

Figura 7. Geração de resíduos sólidos urbanos per capita nas regiões brasileiras $\left(\mathrm{kg}^{-1} \cdot \mathrm{hab}^{-1} \cdot \mathrm{dia}^{-1}\right)$. Fonte: Adaptado de ABRELPE (2017).

A partir desses resultados, realizou-se o levantamento do número de habitantes de cada município, bem como seu Produto Interno Bruto (PIB) per capita (IBGE, 2008), com o objetivo de compreender o comportamento de geração per capita de resíduos sólidos urbanos com relação a tais fatores. É possível observar que a relação entre a produção per capita de resíduos e essas variáveis não apresentam uma correlação significativa para essa região (Figuras 8 e 9). Além disso, o PIB per capita dos municípios apresentam uma certa semelhança. 0 mesmo pode ser observado para o porte, em que $84,6 \%$ dos municípios possuem uma população abaixo de 10.000 habitantes. Contudo, ainda existem diferenças significativas entre as taxas de produção de resíduos, o que possivelmente deve-se às peculiaridades de cada município, bem como a prática de coleta seletiva, uma vez que 
parcela dos resíduos gerados podem não chegar ao aterro sanitário, justamente por não terem sido coletados ou por terem sofrido outra forma de destinação ou disposição.

Tabela 2. Produção per capita de resíduos dos municípios atendidos pelo aterro sanitário de estudo.

\begin{tabular}{|c|c|c|c|c|}
\hline Município & $\begin{array}{c}\text { Resíduos } \\
\text { recebidos }(\mathrm{t})\end{array}$ & $\begin{array}{c}\text { População } \\
\text { (IBGE, 2010) }\end{array}$ & $\begin{array}{c}\text { Geração per capita } \\
\left(\mathrm{kg}^{-1} \cdot \mathrm{hab}^{-1} \cdot \mathrm{d}^{-1}\right)\end{array}$ & $\begin{array}{c}\text { Coleta } \\
\text { seletiva }\end{array}$ \\
\hline Ajuricaba & 60,98 & 7358 & 0,27 & Não \\
\hline Almirante Tamandaré & 16,34 & 2079 & 0,26 & Sim \\
\hline Augusto Pestana & 51,52 & 7091 & 0,24 & Sim \\
\hline Barra Funda & 31,65 & 2516 & 0,41 & Não \\
\hline Boa Vista do Buricá & 51,82 & 6829 & 0,25 & Não \\
\hline Campinas do Sul & 75,9 & 5641 & 0,44 & Sim \\
\hline Chapada & 75,94 & 9597 & 0,26 & Não \\
\hline Condor & 60,98 & 6836 & 0,29 & Não \\
\hline Coqueiros do Sul & 17,32 & 2458 & 0,23 & Sim \\
\hline Carazinho & 938,62 & 62339 & 0,50 & Sim \\
\hline Fortaleza dos Valos & 34,58 & 4588 & 0,25 & Sim \\
\hline Horizontina & 47,96 & 19338 & 0,8 & Sim \\
\hline Independência & 48,12 & 6598 & 0,24 & Sim \\
\hline Não me Toque & 256,46 & 17185 & 0,49 & Não \\
\hline Nova Boa Vista & 24,51 & 1932 & 0,42 & Não \\
\hline Nova Ramada & 10,34 & 2417 & 0,14 & Não \\
\hline Novo Barreiro & 27,92 & 4181 & 0,22 & Não \\
\hline Palmeira das Missões & 563,92 & 34844 & 0,54 & Sim \\
\hline Pejuçara & 49,1 & 4043 & 0,40 & Não \\
\hline Rondinha & 41,82 & 5497 & 0,25 & Sim \\
\hline Santa Bárbara do Sul & 79,56 & 8694 & 0,30 & Sim \\
\hline $\begin{array}{lll}\text { Santo } & \text { Antônio } & \text { do } \\
\text { Planalto } & & \\
\end{array}$ & 23,78 & 2059 & 0,38 & Sim \\
\hline Tapera & 104,5 & 5152 & 0,67 & Sim \\
\hline Tucunduva & 71,60 & 5965 & 0,40 & Sim \\
\hline Victor Graeff & 77,00 & 3051 & 0,84 & Sim \\
\hline XV de novembro & 57,3 & 3826 & 0,49 & Sim \\
\hline Total & 312262 & 242,114 & 0,38 & \\
\hline
\end{tabular}

Embora não tenha sido possível observar uma relação direta entre os fatores avaliados com a geração de resíduos sólidos urbanos per capita quando comparados entre os diferentes municípios dessa pesquisa, estudos já demonstraram a influência de elementos socioeconômicos na alteração da taxa de produção de resíduos sólidos urbanos em cidades, quando avaliadas individualmente. Por exemplo, em Beijing, na China, realizou-se uma avaliação entre a geração per capita diária de resíduos e fatores socioeconômicos. Os autores observaram que o fator de renda apresenta uma relação negativa com a geração de resíduos. Já com relação a educação, agregados familiares que possuíam um nível de ensino secundário produziam menos resíduos que famílias com um nível educacional primário ou avançado ( $Q u$ et al., 2009). Por outro lado, um estudo realizado em um distrito de Jharkhand, na Índia, demonstrou que os grupos enquadrados como classe média geram a maior quantidade de resíduos sólidos (Khan et al., 2016). Ainda, uma avaliação entre a produção de resíduos sólidos urbanos e características 
demográficas, realizada em 6100 municípios da República Checa, concluiu que a produção de resíduos e os recursos necessários para gerenciá-la são fortemente influenciados pela quantidade de idosos aposentados recentemente (Soukopová et al., 2017).

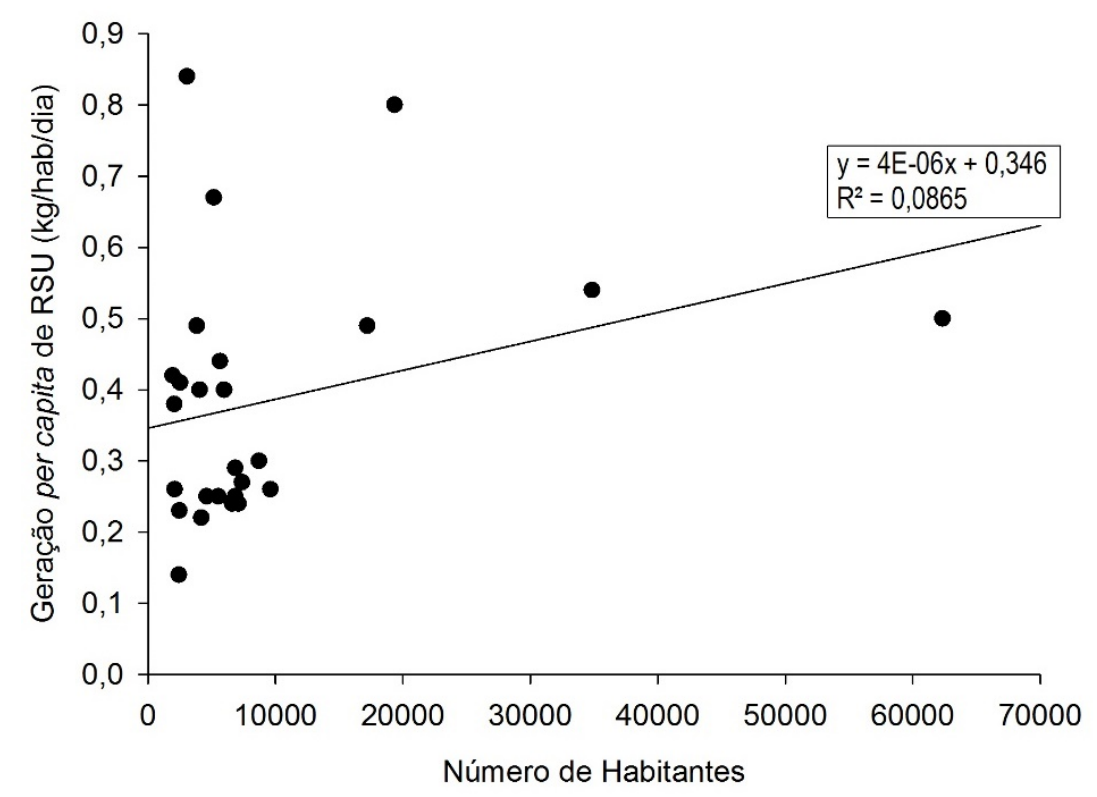

Figura 8. Relação entre o número de habitantes de cada município e a geração per capita de resíduos sólidos urbanos.

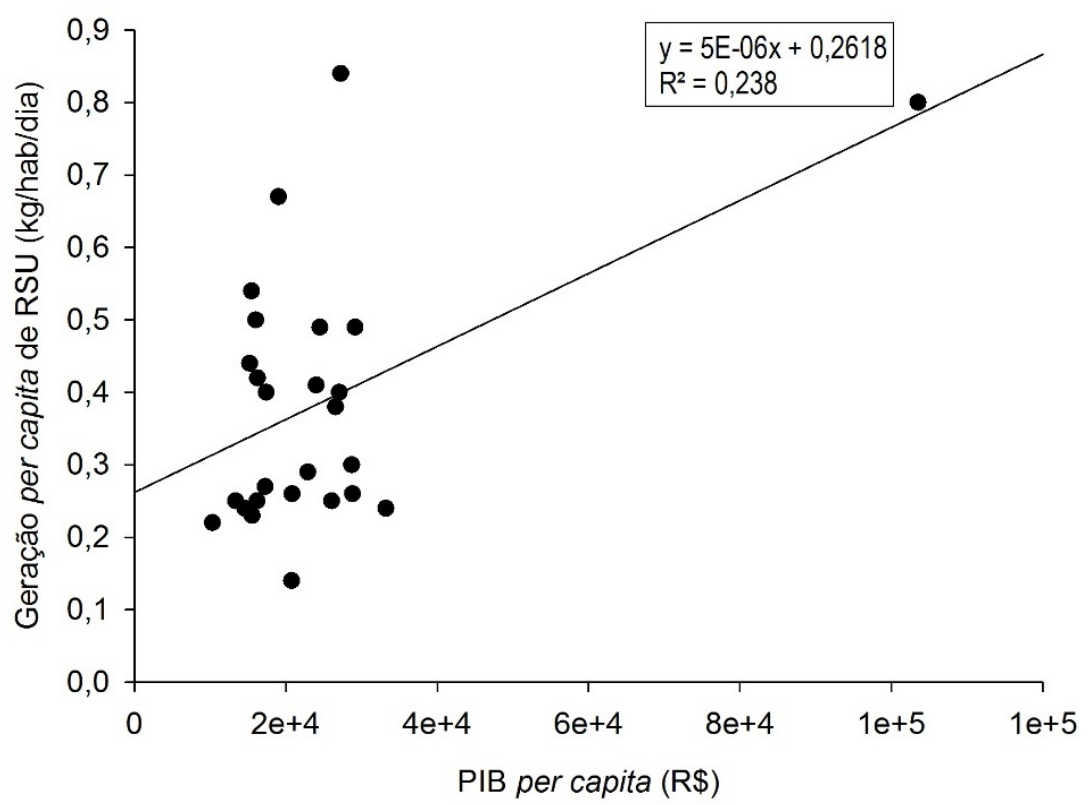

Figura 9. Relação entre o PIB per capita de cada município e a geração per capita de resíduos sólidos urbanos. 
Segundo Campos (2012), a geração média per capita de resíduos sólidos dos países avaliados pela Organização para a Cooperação e Desenvolvimento Econômico (OECD) era $1,41 \mathrm{~kg}^{-1} \cdot \mathrm{hab}^{-1}$.ano ${ }^{-1} \mathrm{em} 2000$. Até esse ano, a produção de resíduos cresceu à medida em que ocorria o aumento do PIB. Posterior a isso, notou-se um crescimento acelerado do PIB, enquanto que a geração de resíduos e a taxa de crescimento populacional decresciam. Apesar de tudo, estima-se que a geração per capita continue a crescer, alcançado um valor médio de $1,90 \mathrm{~kg}^{-1}$.hab ${ }^{-1}$.ano ${ }^{-1}$ em 2030 . Ainda de acordo com o autor, tal fato deve-se, especialmente pelo modelo de desenvolvimento atual, que prevê um crescimento de renda da população mais pobre e um consequente aumento no consumo, sem haver um investimento em políticas de estímulo ao consumo sustentável. De acordo com Wang et al. (2020), a geração per capita está correlacionada principalmente com renda, população e densidade populacional, e é um importante indicador para avaliar a eficiência da gestão de resíduos sólidos urbanos, em que, valores elevados podem representar redução no desempenho do sistema.

Considerando que, para desenvolver um sistema de gerenciamento de resíduos sólidos urbanos adequado, um dos principais fatores à ser determinado é a composição destes resíduos de acordo com as condições ou realidade de um determinado local, sendo importante também, para o estudo de demanda do mercado de produtos recicláveis (Chen et al., 2010). Com base nestas considerações e nos resultados apresentados neste estudo, entende-se que foi possível obter um panorama da geração de resíduos sólidos urbanos dos 27 municípios que os destinam ao aterro sanitário em Palmeira da Missões. Os resultados da composição gravimétrica dos resíduos sólidos urbanos são informações condizentes com a realidade local e necessárias para compreender a dinâmica do sistema de gestão integrada de resíduos sólidos urbanos destes municípios. Também, são importantes subsídios para a elaboração de programas e legislações acerca do referido sistema, incluindo programas para incentivo da coleta seletiva e do desenvolvimento de cooperativas de reciclagem. Além disso, a quantidade de resíduos sólidos urbanos gerada e sua composição são parâmetros técnicos importantes para: a adequada gestão do sistema de triagem e de disposição final; compreensão dos processos envolvidos na decomposição dos resíduos; determinação da vida útil do aterro e ao estudo de viabilidade para tratamento destes resíduos por outras técnicas, como por exemplo, pela compostagem.

\section{Conclusão}

Os resultados da composição gravimétrica dos resíduos sólidos urbanos revelaram que a média dos resíduos orgânicos/rejeitos que são encaminhados para o aterro sanitário aproxima-se da média da região Sul do Brasil e da média nacional, mas correspondem à valores acima da quantidade média de resíduos dos EUA e abaixo de outros países como Quênia, China e Reino Unido.

Já a quantidade de resíduos recicláveis demonstra proporções diferenciadas de outras realidades avaliadas, porém, cabe ressaltar que, somente a parcela desta classe de resíduos corresponde a mais da metade de todo resíduos sólidos urbanos (58,2\%), indicando assim, deficiências nos sistemas de coleta seletiva dos municípios envolvidos, bem como a potencialidade de exploração do mercado de produtos recicláveis. Com relação à porcentagem de resíduos estimados per capita da população, dos municípios atendidos pelo aterro, 7,7\% dos municípios estão acima da média da região sul do Brasil. Quanto a coleta seletiva de resíduos sólidos urbanos, em 37\% dos municípios ainda não ocorre esta prática. Verificou-se também, que o número de habitantes e PIB per capita correlaciona-se de forma pouco significativa com a geração per capita de resíduos sólidos urbanos. 
Por fim, espera-se que este estudo auxilie as instituições públicas e privadas envolvidas no sistema de gerenciamento de resíduos sólidos urbanos dos 27 municípios atendidos pelo aterro sanitário em Palmeira das Missões, fornecendo informações que possam subsidiar o planejamento e o desenvolvimento de projetos acerca dos componentes do referido sistema, desde a coleta até a destinação final, além de programas de educação ambiental e de reciclagem.

\section{Conflito de interesses}

Os autores declaram não haver conflito de interesses.

\section{Referências}

ABNT - Associação Brasileira de Normas Técnicas. ABNT 10004: Resíduos sólidos Classificação. Rio de Janeiro: ABNT, 2004a.

ABNT - Associação Brasileira de Normas Técnicas. ABNT 10007: Amostragem de resíduos sólidos. Rio de Janeiro: ABNT, 2004b.

ABRELPE - Associação Brasileira de Empresas de Limpeza Pública e Resíduos Especiais. Panorama dos Resíduos Sólidos no Brasil 2017. São Paulo: ABRELPE, 2017. Disponível em: <http://abrelpe.org.br/download-panorama-2017/>. Acesso em: 27 fev. 2020.

Agbozu, I.; Oghama, 0.; Odhikori, J. Physico-chemical characterization and pollution index determination of leachates from Warri Waste Dumpsite, Southern Nigeria. Journal of Applied Sciences and Environmental Management, v. 19, p. 361-372, 2015. https://doi.org/10.4314/jasem.v19i3.4

Ahmed, S. A.; Ali, M. Partnerships for solid waste management in developing countries: Linking theories to realities. Habitat International, v. 28, p.467-479, 2004. https://doi.org/10.1016/S0197-3975(03)00044-4

Alfaia, R. G. S. M.; Costa, A. M.; Campos, J. C. Municipal solid waste in Brazil: A review. Waste Management \& Research, v. 35, p. 1195-1209, 2017. https://doi.org/ $10.1177 / 0734242 X 17735375$

Alkmin, D. V.; Uberto Jr, L. U. Determinação da composição gravimétrica dos resíduos sólidos urbanos (RSU) do lixão do Município de Maria da Fé, estado de Minas Gerais. Caminhos de Geografia, v. 18, p. 65-82, 2017.

Barreto, E. V.; Melo, E. S. R. L.; Paiva, G. F. A. V. Análise de composição de resíduos sólidos urbanos como instrumento de gestão em política pública e saneamento. Anais do VI Congresso Brasileiro de Gestão Ambiental, Porto Alegre, Instituto Brasileiro de Estudos Ambientais, Porto Alegre, novembro 2015.

Brasil. Lei no 12.305, de 2 de agosto de 2010. Institui a Política Nacional de Resíduos Sólidos; altera a Lei no 9.605, de 12 de fevereiro de 1998; e dá outras providências. Disponível em: <http://www.planalto.gov.br/ccivil_03/_ato2007-2010/2010/lei/ 112305.htm>. Acesso em: 27 fev. 2020.

Brina, K. R.; Carvalho, T. S.; Ardenghi, P. G.; Basso da Silva, L. Micronuclei and other nuclear anomalies in exfoliated buccal cells of urban solid waste collectors and recyclers in Southern Brazil. Chemosphere, v. 193, p. 1058-1062, 2018. https://doi.org/ 10.1016/j.chemosphere.2017.11.119 
Campos, H. K. T. Renda e evolução da geração per capita de resíduos sólidos no Brasil. Engenharia Sanitaria e Ambiental, v. 17, p. 171-180, 2012. https://doi.org/10.1590/ S1413-41522012000200006

Carvalho, J. L. V.; Jesus, S. C.; Portella, R. B. Composição gravimétrica dos resíduos sólidos domiciliares e comerciais do centro da Cidade de Barreiras - Bahia. Revista Pesquisa Urbana, v. 13, p. 1-23, 2013.

Chen, X.; Geng, Y.; Fujita T. An overview of municipal solid waste management in China. Waste Management, $\quad$ v. 30, p. 716-724, 2010. https://doi.org/10.1016/ j.wasman.2009.10.011

Colazo, A. B.; Sánchez, A.; Font, X.; Colón, J. Environmental impact of rejected materials generated in organic fraction of municipal solid waste anaerobic digestion plants: Comparison of wet and dry process layout. Waste Management, v. 43, p. 84-97, 2015. https://doi.org/10.1016/j.wasman.2015.06.028

Czajczyńska, D.; Nannou, T.; Anguilano, L.; Krzyzyńska, R.; Ghazal, H.; Spencer, N.; Jouhara, $\mathrm{H}$. Potentials of pyrolysis processes in the waste management sector. Energy Procedia, v. 123, p. 387-394, 2017. https://doi.org/10.1016/j.tsep.2017.06.003

Dehghanifard, E.; Dehghani, M. H. Evaluation and analysis of municipal solid wastes in Tehran, Iran. MethodsX, v. 5, p. 312-321, 2018. https://doi.org/10.1016/ j.mex.2018.04.003

Demirbas, A. Waste management, waste resource facilities and waste conversion processes. Energy Conversion and Management, v. 52, p. 1280-1287, 2011. https://doi.org/10.1016/j.enconman.2010.09.025

FAO - Food and Agriculture Organization. Global initiative on food loss and food waste reduction: Key facts on food loss and waste you should know. Rome: FAO, 2016.

Fehr, M. A case study of decentralized household waste management with complete material balance typical of emerging economy contexts. Proceedings Sardinia 2007, Eleventh International Waste Management and Landfill Symposium, Cagliari, 2007.

Gonçalves-Dias, S. L. F. Há vida após a morte: um (re)pensar estratégico para o fim da vida das embalagens. Gestão \& Produção, v. 13, p. 463-474, 2006. https://doi.org/10.1590/ S0104-530X2006000300009

Gutberlet, J. Cooperative urban mining in Brazil: Collective practices in selective household waste collection and recycling. Waste Management, v. 45, p. 22-31, 2015. https://doi.org/10.1016/j.wasman.2015.06.023

He, P.; Chen, L.; Shao, L.; Zhang, H.; Lu, F. Municipal solid waste (MSW) landfill: A source of microplastics? - Evidence of microplastics in landfill leachate. Water Research, v. 159, p. 38-45, 2019. https://doi.org/10.1016/j.watres.2019.04.060

Hoornweg, D.; Bhada-Tata, P. What a waste: A global review of solid waste management. Washington: World Bank, 2012.

Hoque, M. M.; Rahman, M. T. Landfill area estimation based on solid waste collection prediction using ANN model and final waste disposal options. Journal of Cleaner Production, v. 256, p. 1-12, 2020. https://doi.org/10.1016/j.jclepro.2020.120387

IBGE - Insituto Brasileiro de Geografia e Estatística. Produto Interno Bruto dos municipios 2004-2008. Rio de Janeiro: IBGE, 2008.

IPEA - Instituto de Pesquisa Econômica Aplicada. Diagnóstico dos resíduos sólidos urbanos. Brasília: IPEA, 2012. (Relatório de pesquisa). 
Khan, D.; Kumar, A.; Samadder, S. R. Impact of socioeconomic status on municipal solid waste generation rate. Waste Management, v.49, p.15-25, 2016. https://doi.org/ 10.1016/j.wasman.2016.01.019

Lima, M. W.; Surluiga, G. C. Analyses of the city of Rio de Janeiro urban solid waste characteristics. Abstracts of the XXVII Interamerican Congress of Sanitary and Environmental Engineering, Porto Alegre, 2000.

Liu, T.; Wu, Y.; Tian, X.; Gong, Y. Urban household solid waste generation and collection in Beijing, China. Resources, Conservation and Recycling, v. 104, p.31-37, 2015. https://doi.org/10.1016/j.resconrec.2015.09.004

Machado, S. L.; Karimpour-Fard, M.; Shariatmadari, N.; Carvalho, M. F.; Nascimento, J. C. F. Evaluation of the geotechnical properties of MSW in two Brazilian landfills. Waste Management, v. 30, p. 2579-2591, 2010. https://doi.org/10.1016/j.wasman.2010.07.019

Manjunatha, G. S.; Chavan, D.; Lakshmikanthan, P.; Swamy, R.; Kumar, S. Estimation of heat generation and consequent temperature rise from nutrients like carbohydrates, proteins and fats in municipal solid waste landfills in India. Science of the Total Environment, v. 707, p. 1-8, 2020. https://doi.org/10.1016/j.scitotenv.2019.135610

Marshall, R. E.; Farahbakhsh, K. Systems approaches to integrated solid waste management in developing countries. Waste Management, v. 33, p. 988-1003, 2013. https://doi.org/10.1016/j.wasman.2012.12.023

Mattei, G.; Escosteguy, P. A. V. Composição gravimétrica de resíduos sólidos aterrados. Engenharia Sanitária Ambiental, v. 12, p. 247-251, 2007. https://doi.org/10.1590/ S1413-41522007000300003

Melo, V. L. A.; Jucá, J. F. T. Estudos de referência para diagnóstico ambiental em aterros de resíduos sólidos. Anais do XXVII Congresso Interamericano de Engenharia Sanitária e Ambiental, Porto Alegre, 2000.

Miguel, M. G.; Paixão Filho, J. L. D.; Benatti, J. C. B.; Leme, M. A. G.; Mortatti, B. C.; Gabrielli, G.; Elaiuy, M. L. C. Gravimetric composition of municipal solid waste disposed in a largescale experimental cell in Southeastern Brazil. International Journal of Environment and Waste Management, v. 17, p.128-145, 2016. https://doi.org/10.1504/ IJEWM.2016.076758

Mishra, S.; Tiwary, D.; Ohri, A.; Agnihotri A. K. Impact of municipal solid waste landfill leachate on groundwater quality in Varanasi, India. Groundwater for Sustainable Development, v. 9, p. 1-11, 2019. https://doi.org/10.1016/j.gsd.2019.100230

Mohsen, R. A.; Abbassi, B. Prediction of greenhouse gas emissions from Ontario's solid waste landfills using fuzzy logic based model. Waste Management, v. 102, p. 743-750, 2020. https://doi.org/10.1016/j.wasman.2019.11.035

Monteiro, V. E. D.; Jucá, J. F. T. Gestão ambiental no processo de recuperação da área do aterro de resíduos sólidos da Muribeca. Anais do III Encontro da Sociedade Brasileira de Economia Ecológica, Recife, 1999.

Münnich, K.; Mahler, C. F.; Fricke, K. Pilot project of mechanical-biological treatment of waste in Brazil. Waste Management, v. 26, p. 150-157, 2006. https://doi.org/10.1016/ j.wasman.2005.07.022

Obe, R. K. D.; Brito, J.; Lynn, C. J.; Silva, R. V. Sustainable construction materials: Municipal incinerated bottom ash. Sawston: Woodhead Publishing, 2017. 
Oyake-Ombis, L.; van Vliet, B. J. M.; Mol, A. P. J. Managing plastic waste in East Africa: Niche innovations in plastic production and solid waste. Habitat International, v. 48, p. 188-197, 2015. https://doi.org/10.1016/j.habitatint.2015.03.019

Pellera, F. M.; Pasparakis, E.; Gidarakos, E. Consecutive anaerobic-aerobic treatment of the organic fraction of municipal solid waste and lignocellulosic materials in laboratory-scale landfill-bioreactors. Waste Management, v. 56, p.181-189, 2016. https://doi.org/ 10.1016/j.wasman.2016.07.044

Puna, J. F. B.; Baptista, B. S. A gestão integrada de resíduos sólidos urbanos: perspectiva ambiental e econômico-energética. Química Nova, v. 31, p.645-654, 2008. https://doi.org/10.1590/S0100-40422008000300032

Qu, X. Y.; Li, Z. S.; Xie, X. Y.; Sui, Y. M.; Yang, L.; Chen, Y. Survey of composition and generation rate of household wastes in Beijing, China. Waste Management, v. 29, p. 2618-2624, 2009. https://doi.org/10.1016/j.wasman.2009.05.014

Slagstad, H.; Brattebø, H. Influence of assumptions about household waste composition in waste management LCAs. Waste Management, v. 33, p. 212-219, 2013. https://doi.org/ 10.1016/j.wasman.2012.09.020

Soukopová, J.; Struk, M.; Hřebíček, J. Population age structure and the cost of municipal waste collection. A case study from the Czech Republic. Journal of Environmental Management, v. 203, p. 655-663, 2017. https://doi.org/10.1016/j.jenvman.2016.03.030

Tirado-Soto, M. M.; Zamberlan, F. L. Networks of recyclable material waste-picker's cooperatives: An alternative for the solid waste management in the City of Rio de Janeiro. Waste Management, v. 33, p.1004-1012, 2013. https://doi.org/10.1016/ j.wasman.2012.09.025

Torrente-Valásquez, J. M.; Chifari, R.; Ripa, M.; Giampero, M. Robust information for effective municipal solid waste policies: Identifying behaviour of waste generation across spatial levels of organization. Waste Management, v. 103, p.208-217, 2020. https://doi.org/10.1016/j.wasman.2019.12.032

Wang, Z.; Dong, X.; Yin, J. Antecedents of urban residents' separate collection intentions for household solid waste and their willingness to pay: Evidence from China. Journal of Cleaner Production, v. 173 , p. 256-264, 2018. https://doi.org/10.1016/ j.jclepro.2016.09.223

Wang, D.; Tang, Y.; Long, G.; Higgitt, D.; He, J.; Robinson, D. Future improvements on performance of an EU landfill directive driven municipal solid waste management for a city in England. Waste Management, v. 102, p. 452-463, 2020. https://doi.org/10.1016/ j.wasman.2019.11.009

Zhao, Y.; Christensen, T. H.; Lu, W.; Wu, H.; Wang H. Environmental impact assessment of solid waste management in Beijing City, China. Waste Management, v. 31, p. 793-799, 2011. https://doi.org/10.1016/j.wasman.2010.11.007

Zhou, H.; Meng, A.; Long, Y.; Li, Q.; Zhang, Y. An overview of characteristics of municipal solid waste fuel in China: Physical, chemical composition and heating value. Renewable and Sustainable Energy Reviews, v. 36, p. 107-122, 2014. https://doi.org/ 10.1016/j.rser.2014.04.024

Informação da Licença: Este é um artigo Open Access distribuído sob os termos da Licença Creative Commons Attribution, que permite uso irrestrito, distribuição e reprodução em qualquer meio, desde que a obra original seja devidamente citada. 